\title{
Fatigue and weakness hinder patient social reintegration after liver transplantation
}

\author{
So Hyun Kang1, YoungRok Choi, ${ }^{1,2}$, Ho-Seong Han ${ }^{1,2}$, Yoo-Seok Yoon ${ }^{1,2}$, Jai Young Cho ${ }^{1,2}$, Sungho Kim', Kil Hwan Kim', \\ In Gun Hyun', and Ahmed Shehta ${ }^{3}$
}

'Department of Surgery, Seoul National University Bundang Hospital, Seongnam; ${ }^{2}$ Department of Surgery, Seoul National University College of Medicine, Seoul, Korea, ${ }^{3}$ Gastrointestinal Surgery Center, Department of Surgery, Mansoura University College of Medicine, Dakahlia Governorate, Egypt

Background/Aims: With improvements in the survival of liver transplantation (LT) recipients, the focus is shifting to patient quality of life (QOL), and employment is an important factor in aiding the social reintegration of LT patients. This study aims to evaluate the current employment status of liver graft recipients and various factors that may hinder reemployment.

Methods: Fifty patients above age 18 who underwent either living or deceased donor LT at a single center from March 2009 to July 2016 were interviewed during their visit to the outpatient clinic. The internally developed questionnaire consisted of 10 items. The Karnofsky Performance Scale and EQ-5D were used to evaluate patient function and QOL.

Results: A total of 25 (50\%) patients returned to work after transplantation (the working group), and 21 (84\%) patients in the working group returned to work within the first year after transplantation. In the non-working group $(n=25), 17(68 \%)$ answered that their health was the reason for unemployment. Fatigue and weakness were the most frequent symptoms.

Conclusions: The data shows that as many as $50 \%$ of total patients returned to work after receiving LT. Fatigue and weakness were the most common complaints of the unemployed group, and resolving the causes of these symptoms may help to increase the employment rate. (Clin Mol Hepatol 2018;24:402-408)

Keywords: Liver transplantation; Employment; Quality of life

\section{Study Highlights}

As many as half of liver transplantation recipients remain unemployed after the operation. Health was the main cause of unemployment with fatigue and weakness as the most frequently complained symptoms.

\section{INTRODUCTION}

In Asian countries, cases of liver transplantation (LT) has rapidly increased due to increasing numbers of living donor liver transplantation (LDLT) patients. ${ }^{1}$ Due to advances in immunosuppressants and surgical techniques, both LDLT and deceased donor liv-

\section{Abbreviations:}

DDLT, deceased donor liver transplantation; IRB, institutional review board; LDLT, living donor liver transplantation; LT, liver transplantation; MELD, Model for End-stage Liver Disease; QOL, quality of life; UNOS, United Network for Organ Sharing

\section{Corresponding author : YoungRok Choi}

Department of Surgery, Seoul National University Bundang Hospital, 82 Gumi-ro 173beon-gil, Bundang-gu, Seongnam 13620, Korea

Tel: +82-31-787-7111, Fax: +82-31-787-4055

E-mail: choiyoungrok@gmail.com

https://orcid.org/0000-0003-2408-7086 
er transplantation (DDLT) now showed good overall survival rates. ${ }^{2}$ Therefore, many professionals in $\mathrm{LT}$ are shifting their focus from prolonging the life expectancy to restoring the social quality of life (QOL). A possible measure of the proper social reintegration of LT patients is employment.

Huda et al. examined the United Network for Organ Sharing (UNOS) data registry, and out of the 21,942 LT recipients, 5,360 patients (24\%) were employed within 2 years from LT. ${ }^{3}$ Several studies showed that a previous working status was a significant factor in predicting employment after LT, while Model for Endstage Liver Disease (MELD) scores were not predictive of future employment. ${ }^{4,5}$

Although several studies such as above have been performed to analyze employment after LT, there are, so far, no studies in Korea that explore the postoperative employment or other social reintegration of the LT patients. Also, none of the previous studies have not included housewives as a job, and the specific symptoms which might be the reason for unemployment were not surveyed in detail. This study aims to analyze current employment status of living and deceased donor liver transplant recipients and discuss the factors that may contribute to it.

\section{MATERIALS AND METHODS}

This study was designed as a cross-sectional study. Patients above age 18 and under 65 who underwent LT in single center of Seoul National University Bundang Hospital from March 2009 to July 2016 were asked to fill a survey regarding employment status and QOL. The survey consisted of an internally developed questionnaire of 10 questions regarding employment (Fig. 1, Supplementary Fig. 1) that were influenced by previously reported surveys regarding employment. ${ }^{3,6,7}$ Patients also filled out the previously verified EQ-5D and Karnofsky scale questionnaires to evaluate for patient QOL. All the surveys were delivered to the patients by the primary investigator, and after a brief explanation, patients were given time to answer the questions by themselves. Medical records were reviewed for laboratory data and post-operative course retrospectively on electronic medical records. The date of normalization of liver test was defined as the first date when all of serum total bilirubin, aspartate aminotransferase, alanine aminotransferase, gamma-glutamyltransferase, and prothrombin time international normalized ratio reached to within normal limits. For patients who were transplanted for liver malig-
Please answer the following questions according to your employment status.

If you are currently working, please answer questions 1 to 6 . (This includes housewives and students.)

1. What is your working status?

A. Full-time

B. Part-time

C. Housewife/student

2. What is your job?

3. How long did it take until you started working again?

A. Less than 3 months

B. 3-6 months

C. 6-12 months

D. 1-2 years

E. More than 2 years

4. Were you working before undergoing transplantation?

A. Yes

B. No

5. If you answered yes above, is it the same job as you have right now?

A. Yes

B. No

C. I had no job before transplantation.

6. How is your income compared to before transplantation?

A. Less than before transplantation

B. Same as before transplantation

C. More than before transplantation
If you are unemployed, please answer question 7 to 10.

7. Are you retired?

A. Yes

B. No

8. If not, are you currently looking for a job?

A. Yes

B. No

9. What do you think is the reason for your unemployment?

10. If you answered health, what hinders you from working again? You can check as many items as you want.

A. Fatigue

B. Weakness

C. Pain

D. Jaundice

E. Ascites

F. Dialysis

G. Frequent visits to the hospital

H. Medication

।. Others

Figure 1. Internally developed questionnaire translated into English. 
nancies, none of the patients had recurrence of hepatocellular carcinoma or other malignancies at the time of the survey. Analysis was performed using SPSS ver. 18.0 (IBM Corp., Armonk, NY, USA) software package. For continuous variables, the $t$-test or the Mann-Whitney $U$ test was used, and for categorical variables, the $\chi 2$ test or the Fischer's exact test was performed. This research was approved by the institutional review board (IRB) of Seoul National University Bundang Hospital (SNUBH, B-1609-361-301). Patients were explained by the main researchers, and were given formal written consent forms. All investigations were held according declaration of Helsinki and the ethical requirements of the IRB.

\section{RESULTS}

A total of 50 patients responded to the survey. Among them, half $(n=25)$ of the patients were employed at the time of the survey (the employed group). There was no difference in the mean age between the working group and the unemployed group (Table 1). In the employed group, $96 \%$ of them were previously employed within 12 months before having LT, while in the unemployed group, only $60 \%$ were previously employed. There was no significant difference of MELD scores at the time of LT or at the time of survey between the two groups, and there was no difference of the etiologies of the liver disease between the two groups. The time at survey between the two groups was different; the unemployed group took the survey at mean postoperative $534.0 \pm 453.9$ days while the employed group had taken the survey at mean postoperative $915.5 \pm 773.8$ days $(P$-value $=0.04)$. The demographics of the employed and unemployed group are described in Table 1. The detailed job classifications can be seen in Supplementary Table 1.

Table 2 showed the clinical characteristics of the two groups. Hospital stay was slightly shorter ( $23.24 \pm 15.16$ vs. $25.56 \pm 13.57$, $P=0.571)$ and Karnofsky scale was higher (87.40 \pm 8.55 vs. $83.60 \pm 12.87, P=0.226$ ) in the working group, but both showed no statistical significance.

Among the currently employed patients, $80 \%(n=20)$ returned to their previous jobs. Patients who had received LDLT showed faster return to work than those who had received DDLT. $40 \%$ of patients who returned to their previous jobs in the employed group $(n=10)$ expressed that they had lower income than before $L T$, while $48 \%(n=12)$ of the patients reported that they had similar income as compared to before LT (Table 3). Most of patients returned to their jobs within the first year after surgery. $25 \%$ of them returned to working status within the first 3 months. There was also a significant difference of MELD scores between the LDLT and the DDLT group (15.8 \pm 8.5 vs. $27.9 \pm 11.4, P=0.006)$.

Table 4 described the characteristics of the unemployed patients. Although $72 \%(n=18)$ of the unemployed group answered themselves not retired, only $12 \%(n=3)$ were actively looking for jobs. $68 \%$ ( $n=17)$ pointed out health as the major factor for their unemployment. When asked to check on any of the symptoms that seem to inhibit their re-employment, fatigue and muscle weakness topped with 13 patients complaining of the symptoms. It was then followed by pain (Table 5).

\section{DISCUSSION}

Since the first successful LT in $1969,{ }^{8}$ much of the procedure and the medical therapy have improved to establish LT as an effective treatment for end-stage liver disease. This analysis showed that even after LT, only half of the patients could return to employment. Although the sample size is small in this study, this study had a greater percentage than what was previously reported in other countries. ${ }^{3,9}$ Patients who received LDLT returned to work faster as compared to those who received DDLT. However, there was no statistical difference in the factors involved between the employed and unemployed groups. Most of the patients in the unemployed group expressed fatigue and muscle weakness as primary symptoms.

Despite increasing numbers of organ donation, the number of cadaveric liver donors are still not enough to fulfill the demand of end-stage liver disease patients. ${ }^{10}$ Hence, LDLT is being performed intensively in South Korea. In this survey, recipients who underwent LDLT returned to work faster. Than those who received DDLT. This is most probably due to the difference in disease progression of the LDLT group and the DDLT group shown by the difference in MELD scores before LT. The patients who underwent DDLT usually have severe disease progression along with an aggravated liver function, and many patients in the LDLT group even have almost normal liver function such as Child-Pugh class $A$, before transplantation. Although there was no difference in the MELD score between the employed and unemployed groups, this indicated that the severity of disease progression before LT could be a factor in slowing down the social integration of patients.

Fatigue and muscle weakness were the most frequently symptoms of the unemployed patients. Fatigue is a common symptom 
Table 1. Demographics of employed and unemployed patients after liver transplantation (LT)

\begin{tabular}{|c|c|c|c|}
\hline & Unemployed $(n=25)$ & Employed $(n=25)$ & $P$-value \\
\hline Gender (n, \%) & & & 0.54 \\
\hline Female & $6(24.0)$ & $9(36.0)$ & \\
\hline Male & $19(76.0)$ & $16(64.0)$ & \\
\hline Age at LT (years) & $54.2 \pm 10.4$ & $51.0 \pm 9.0$ & 0.25 \\
\hline Age at survey (years) & $55.6 \pm 10.7$ & $53.5 \pm 9.3$ & 0.46 \\
\hline Postoperative day at survey (days) & $534.0 \pm 453.9$ & $915.5 \pm 773.8$ & 0.04 \\
\hline Education level $(n, \%)$ & & & 0.19 \\
\hline No education & $0(0.0)$ & $1(3.8)$ & \\
\hline Elementary school & $2(8.3)$ & $4(15.4)$ & \\
\hline Middle school & $5(20.8)$ & $2(7.7)$ & \\
\hline High school & $8(33.3)$ & $10(38.5)$ & \\
\hline Community college & $1(4.2)$ & $0(0.0)$ & \\
\hline College & $8(33.3)$ & $5(19.2)$ & \\
\hline Graduate school & $0(0.0)$ & $4(15.4)$ & \\
\hline Marital status (n, \%) & & & 0.55 \\
\hline Married & $20(80.0)$ & $19(76.0)$ & \\
\hline Unmarried & $2(8.0)$ & $2(8.0)$ & \\
\hline Divorced & $2(8.0)$ & $2(8.0)$ & \\
\hline Widowed & $0(0.0)$ & $2(8.0)$ & \\
\hline Cohabitation & $1(4.0)$ & $0(0.0)$ & \\
\hline Disease entity (n, \%) & & & 0.55 \\
\hline Malignancy & $11(44.0)$ & $9(36.0)$ & \\
\hline Alcoholic & $3(12.0)$ & $5(20.0)$ & \\
\hline Hepatitis B & $7(28.0)$ & $4(16.0)$ & \\
\hline Hepatitis A & $0(0.0)$ & $1(4.0)$ & \\
\hline Hepatitis C & $1(4.0)$ & $0(0.0)$ & \\
\hline Hepatitis E & $0(0.0)$ & $1(4.0)$ & \\
\hline Autoimmune & $1(4.0)$ & $2(8.0)$ & \\
\hline Toxic & $1(4.0)$ & $0(0.0)$ & \\
\hline Others & $1(4.0)$ & $3(12.0)$ & \\
\hline MELD scores before LT & $18.0 \pm 12.9$ & $20.2 \pm 11.1$ & 0.54 \\
\hline MELD scores at survey & $8.6 \pm 2.5$ & $9.8 \pm 5.9$ & 0.09 \\
\hline Type of graft $(n, \%)$ & & & 1.00 \\
\hline Deceased & $10(40.0)$ & $9(36.0)$ & \\
\hline Living & $15(60.0)$ & $16(64.0)$ & \\
\hline
\end{tabular}

Values are presented as mean \pm SD or $n(\%)$ unless otherwise indicated. MELD, Model for End-stage Liver Disease.

of liver disease, and several studies show that undergoing LT is associated with improvement of fatigue." However, various reports also showed that fatigue was still the most common persist- ing symptom even after $\mathrm{LT}^{12}$ and affects social life and health related QOL. Fatigue is a complex symptom, which may be caused by both physical and mental state, including poor sleep quality 
Table 2. Clinical performance of employed and unemployed groups

\begin{tabular}{lccc}
\hline & Unemployed $(\mathbf{n}=\mathbf{2 5})$ & Employed $(\mathbf{n}=\mathbf{2 5})$ & $\boldsymbol{P}$-value \\
\hline Karnofsky Performance Scale & $83.6 \pm 12.9$ & $87.4 \pm 8.6$ & 0.23 \\
Hospital stay (postoperative days) & $25.6 \pm 13.6$ & $23.1 \pm 15.2$ & 0.55 \\
\hline First normal liver function test after LT (postoperative day) & $25.1 \pm 35.1$ & $16.8 \pm 16.5$ & 0.32 \\
EQ-5D score & $71.4 \pm 19.7$ & $77.6 \pm 13.3$ & 0.20 \\
\hline
\end{tabular}

Values are presented as mean \pm SD unless otherwise indicated.

$\mathrm{LT}$, liver transplantation.

Table 3. Employment status of working recipients

\begin{tabular}{|c|c|c|c|c|}
\hline Type of graft & Deceased $(n=9)$ & Living $(n=16)$ & Total $(n=25)$ & $P$-value \\
\hline Employment type (n, \%) & & & & 0.15 \\
\hline Fulltime & $3(33.3)$ & $11(68.8)$ & $14(56.0)$ & \\
\hline Part-time & $2(22.2)$ & $3(18.8)$ & $5(20.0)$ & \\
\hline Houseworker/student & $4(44.4)$ & $2(12.5)$ & $6(24.0)$ & \\
\hline Time getting back to work (n, \%) & & & & 0.03 \\
\hline Less than 3 months & $1(11.1)$ & $5(33.3)$ & $6(25.0)$ & \\
\hline 3-6 months & $6(66.7)$ & $1(6.7)$ & $7(29.2)$ & \\
\hline 6-12 months & $2(22.2)$ & $5(33.3)$ & $7(29.2)$ & \\
\hline $1-2$ years & $0(0.0)$ & $3(20.0)$ & $3(12.5)$ & \\
\hline More than 2 years & $0(0.0)$ & $1(6.7)$ & $1(4.2)$ & \\
\hline Employment status before transplantation ( $n, \%)$ & & & & 0.77 \\
\hline Employed & $8(88.9)$ & $16(100.0)$ & $24(96.0)$ & \\
\hline Unemployed & $1(11.1)$ & $0(0.0)$ & $1(4.0)$ & \\
\hline Job before transplantation (n, \%) & & & & 0.47 \\
\hline Same job & $6(66.7)$ & $14(87.5)$ & $20(80.0)$ & \\
\hline Different job & $3(33.3)$ & $2(12.5)$ & $5(20.0)$ & \\
\hline Change of income $(n, \%)$ & & & & 0.11 \\
\hline Less than before LT & $6(66.7)$ & $4(25.0)$ & $10(40.0)$ & \\
\hline Same as before LT & $2(22.2)$ & $10(62.5)$ & $12(48.0)$ & \\
\hline More than before LT & $1(11.1)$ & $2(12.5)$ & $3(12.0)$ & \\
\hline MELD scores before LT & $27.9 \pm 11.4$ & $15.8 \pm 8.5$ & $20.2 \pm 11.1$ & 0.01 \\
\hline
\end{tabular}

Values are presented as mean \pm SD or $n(\%)$ unless otherwise indicated.

LT, liver transplantation; MELD, Model for End-stage Liver Disease.

and depression. An interesting study by Aadahl et al. showed that fatigue after LT was mostly physical, and that employment was significantly associated with less physical fatigue. ${ }^{13}$ This study supported the idea that patients with a high degree of physical fatigue will most likely retire or stay unemployed, but also suggests that patients who are unemployed may be less stimulated than the working group, and may experience more fatigue.

Some reports of rehabilitation programs for liver transplant recipients have been found in literature. ${ }^{14}$ A study by van den Berg-
Emons et al. describes how fatigue is improved by a 12-week rehabilitation program including exercises and physical activity. ${ }^{15}$ Fatigue was analyzed using three validated scales, and the results showed that the rehabilitation program reduced fatigue from $53 \%$ to $22 \%$. Other evidences also supported the functional gain of LT patients after a rehabilitation program using the functional independence measure scores. ${ }^{14}$ There are rehabilitation programs directed specially for the alcoholic patient group to avoid recurrence of alcoholic liver cirrhosis. ${ }^{16}$ An analysis of the UNOS data- 
Table 4. Employment status of non-working recipients

\begin{tabular}{|c|c|c|c|c|}
\hline Type of graft & Deceased $(n=10)$ & Living $(n=15)$ & Total $(n=25)$ & $P$-value \\
\hline Retirement $(n, \%)$ & & & & 0.79 \\
\hline Retired & $2(20.0)$ & $5(33.3)$ & $7(28.0)$ & \\
\hline Not retired & $8(80.0)$ & $10(66.7)$ & $18(72.0)$ & \\
\hline Actively looking for job (n, \%) & & & & 0.38 \\
\hline Yes & $0(0.0)$ & $3(20.0)$ & $3(12.0)$ & \\
\hline No & $10(100.0)$ & $12(80.0)$ & $22(88.0)$ & \\
\hline Reason for unemployment (n, \%) & & & & 0.39 \\
\hline Health & $9(90.0)$ & $8(53.3)$ & $17(68.0)$ & \\
\hline Other than health & $1(0.0)$ & $7(46.7)$ & $8(32.0)$ & \\
\hline
\end{tabular}

Values are presented as $n(\%)$ unless otherwise indicated.

Table 5. Most frequent symptoms that hinder employment

\begin{tabular}{lc}
\hline Common symptoms & Number of patients $(\mathbf{n}=\mathbf{1 7})$ \\
\hline Fatigue & $13(76.5)$ \\
Weakness & $13(76.5)$ \\
\hline Pain & $7(41.2)$ \\
\hline Frequent visits to the hospital & $4(23.5)$ \\
\hline Medication & $3(17.6)$ \\
\hline Ascites & $2(11.7)$ \\
Jaundice & $0(0.0)$ \\
Dialysis & $0(0.0)$ \\
\hline Other & $0(0.0)$ \\
\hline
\end{tabular}

Values are presented as $n$ (\%).

base described how patients with alcoholic liver disease had a significantly lower rate of employment compared with other disease entities. ${ }^{3}$ Although this survey did not show a difference between disease etiology due to small sample size, LT patients who had alcoholic liver cirrhosis must be guided to a special rehabilitation program to support their social reintegration.

This study had several limitations. Firstly, the sample size of 50 patients was too small to show statistical significance. Perhaps a multi-center survey can be done, or, even better, a large database of transplantation patients and their employment status can be formed using database of the Korean Network for Organ Sharing. Also, the survey consisted of questions mostly regarding employment. While the survey used validated items such as the EQ-5D and the Karnofky scores, the main survey itself is not a validated survey. To overcome this weakness, most of the questionnaire was based on previously performed studies regarding employment on transplantation patients. ${ }^{3,6,7}$ The time difference of the survey between the two groups could imply that if the unemployed group had taken their survey one year later, the results may have been different. It could imply that there is a one-year time difference between the employed and the unemployed group. Furthermore, although employment is one of the most crucial factors in assessing social adaptation, interaction with their family and other members of the society, confidence and psychological state of mind also contribute to social status. For future studies, social reintegration and psychosocial wellbeing of liver donors may be surveyed and analyzed.

Despite the limitations described above, this study analyzes employment status including homeworkers and students as employed. Also, it delves into the main reason patients complain of unemployment - fatigue and muscle weakness. LT is no longer a synonym for inability. With improving graft survival, several patients are now finding their way back into society and productive lives. Although half of the LT recipients return to employment, still several are finding difficulty returning to their previous position in society. Rehabilitation programs may be helpful in assisting their social rehabilitation.

In this single-center study, $50 \%$ of patients still remain unemployed after receiving LT. Most of them expressed fatigue and muscle weakness as symptoms that hinder their recovery into work society. Rehabilitation programs that focus on reducing fatigue and improving physical function may be helpful in the social reintegration of liver transplant recipients, but further studies and objective evidences are needed to prove that it will provide aid in increasing employment rate.

\section{Authors' contribution}

Idea by YoungRok Choi. 
Planning, data collection by YoungRok Choi and So Hyun Kang.

Analysis and data management by So Hyun Kang, Ho-Seong Han, Yoo-Seok Yoon, Jai Young Cho, Sungho Kim, Kil Hwan Kim, In Gun Hyun, and Ahmed Shehta.

Manuscript writing and revision by So Hyun Kang, YoungRok Choi, Ho-Seong Han, Yoo-Seok Yoon, and Jai Young Cho.

\section{Conflicts of Interest}

The authors have no conflicts of interest to disclose.

\section{SUPPLEMENTARY MATERIALS}

Supplementary materials are available at Clinical and Molecular Hepatology website (http://www.e-cmh.org).

\section{REFERENCES}

1. Lee SG, Moon DB, Hwang S, Ahn CS, Kim KH, Song GW, et al. Liver transplantation in Korea: past, present, and future. Transplant Proc 2015:47:705-708

2. Jain A, Reyes J, Kashyap R, Dodson SF, Demetris AJ, Ruppert K, et al. Long-term survival after liver transplantation in 4,000 consecutive patients at a single center. Ann Surg 2000;232:490-500.

3. Huda A, Newcomer R, Harrington C, Blegen MG, Keeffe EB. High rate of unemployment after liver transplantation: analysis of the United Network for Organ Sharing database. Liver Transplantation 2012:18:89-99.

4. Huda A, Newcomer R, Harrington C, Keeffe EB, Esquivel CO. Employment after liver transplantation: a review. Transplant Proc 2015;47:233-239.

5. Onghena L, Develtere W, Poppe C, Geerts A, Troisi R, Vanlander $A$, et al. Quality of life after liver transplantation: state of the art.
World J Hepatol 2016;8:749-756.

6. Eng M, Zhang J, Cambon A, Marvin MR, Gleason J. Employment outcomes following successful renal transplantation. Clin Transplant 2012;26:242-246.

7. Rongey C, Bambha K, Vanness D, Pedersen RA, Malinchoc M, Therneau TM, et al. Employment and health insurance in long-term liver transplant recipients. Am J Transplant 2005;5:1901-1908.

8. Starzl TE, Brettschneider L, Penn I, Bell P, Groth CG, Blanchard $\mathrm{H}$, et al. Orthotopic liver transplantation in man. Transplant Proc 1969;1:216-222.

9. Rudler M, Rousseau G, Lebray P, Méténier O, Vaillant JC, Savier E, et al. Rate of employment after liver transplantation in France: a single-centre study. Eur J Gastroenterol Hepatol 2016;28:159-163.

10. Korean Network for Organ Sharing (KONOS). 2016 Annual Report. KONOS web site, <https://www.konos.go.kr/konosis/index.jsp>. Accessed 10 Jan 2017.

11. van den Berg-Emons R, van Ginneken B, Wijffels M, Tilanus H, Metselaar $\mathrm{H}$, Stam $\mathrm{H}$, et al. Fatigue is a major problem after liver transplantation. Liver Transpl 2006;12:928-933.

12. Hong K, Kim H, Lee JM, Lee KW, Yi NJ, Lee HW, et al. Fatigue and related factors after liver transplantation. Korean J Hepatobiliary Pancreat Surg 2015;19:149-153.

13. Aadahl M, Hansen BA, Kirkegaard P, Groenvold M. Fatigue and physical function after orthotopic liver transplantation. Liver Transpl 2002;8:251-529.

14. Cortazzo MH, Helkowski W, Pippin B, Boninger ML, Zafonte R. Acute inpatient rehabilitation of 55 patients after liver transplantation. Am J Phys Med Rehabil 2005;84:880-884.

15. van den Berg-Emons RJ, van Ginneken BT, Nooijen CF, Metselaar HJ, Tilanus HW, Kazemier G, et al. Fatigue after liver transplantation: effects of a rehabilitation program including exercise training and physical activity counseling. Phys Ther 2014;94:857-865.

16. Everhart JE, Beresford TP. Liver transplantation for alcoholic liver disease: a survey of transplantation programs in the United States. Liver Transpl Surg 1997;3:220-226. 